\title{
Reciprocal Regulation of Ciliary Neurotrophic Factor Receptors and Acetylcholine Receptors during Synaptogenesis in Embryonic Chick Atria
}

\author{
Xin Wang and Stanley W. Halvorsen \\ Department of Biochemical Pharmacology, School of Pharmacy, State University of New York at Buffalo, Buffalo, \\ New York 14260-1200
}

Ciliary neurotrophic factor (CNTF) has been implicated in the development, survival, and maintenance of a broad range of neurons and glia in the peripheral nervous system and the CNS. Evidence also suggests that CNTF may affect development of cells outside the nervous system. We have found that functional CNTF and its receptor are expressed in developing embryonic chick heart and may be involved in parasympathetic synapse formation. CNTF and CNTF receptor mRNA levels were highest at embryonic day 11 (E11)-E13, the period of parasympathetic innervation in chick atria. Levels of atrial CNTF receptor mRNA were fourfold greater at E13 than at E6 and at E13 were 2.5-fold higher in atria than in ventricle, corresponding to the higher degree of parasympathetic innervation occurring in atria. Treatment of isolated atria or cultured atrial myocytes with recombinant human or avian CNTF resulted in the tyrosine phosphorylation and nuclear translocation of the signal transducer and activator of transcription STAT3. The developmental increase in atrial CNTF receptor mRNA was enhanced by stimulating muscarinic receptors with carbachol in ovo and was inhibited by blocking muscarinic cholinergic receptors with atropine. Treatment of cultured atrial myocytes with CNTF resulted in a twofold increase in the levels of muscarinic receptors. Thus, CNTF was able to regulate a key component of parasympathetic synapses on atrial myocytes. These results suggest a postsynaptic role for CNTF in the onset of parasympathetic function in the developing heart and provide new clues to molecular mechanisms directing synapse formation at targets of the autonomic nervous system.

Key words: parasympathetic; STAT; CNTF; heart development; synapse formation; cardiomyocyte; cytokines; receptor regulation
In the vertebrate heart, there is robust parasympathetic innervation of atria that inhibits pacemaker activity, atrial contractility, and atrioventricular conduction. Relatively little is known, however, about the fundamental mechanisms for establishing parasympathetic synapses in the heart (Hirst et al., 1996). Recently, a new class of potential cardiac and/or neurotrophic factors, the neuropoietic cytokines, was described (Kishimoto et al., 1994). This group of mammalian factors, including ciliary neurotrophic factor (CNTF), its avian counterpart [growth-promoting activity (GPA)], leukemia inhibitory factor (LIF), oncostatin M, interleukin 6 , interleukin 11, and cardiotrophin 1, displays some common biological activities, has structural similarities, and shares receptor subunits and signal transduction pathways (Kishimoto et al., 1992; Leung et al., 1992; Stahl and Yancopoulos, 1993; Fann and Patterson, 1994; Pennica et al., 1995; Symes et al., 1997).

CNTF was identified, purified, and cloned based on its neurotrophic activity for parasympathetic neurons of cultured embryonic chick ciliary ganglia (Adler et al., 1979; Lin et al., 1989; Stöckli et al., 1989; Leung et al., 1992). The known receptor

Received March 5, 1998; revised June 11, 1998; accepted July 2, 1998.

This work was supported by National Institutes of Health Grant NS30232 and National Science Foundation Grant IBN9210348 to S.W.H. and by a grant from the Mark Diamond Fund of the State University of New York-Buffalo Graduate School to X.W. We thank Regeneron Pharmaceuticals for recombinant human CNTF, John Bixby for the anti-synapsin I antibody, and Rae Nishi for avian CNTF and the probe for avian CNTF mRNA.

Correspondence should be addressed to Dr. Stanley W. Halvorsen, Department of Biochemical Pharmacology, 447 Hochstetter Hall, Box 601200, State University of New York at Buffalo, Buffalo, NY 14260-1200.

Copyright (ㄷ) 1998 Society for Neuroscience $0270-6474 / 98 / 187372-09 \$ 05.00 / 0$ complex for the CNTF-related cytokines includes gp130 as a signal transducer and, except for interleukin 6 and 11, the LIF receptor $\beta$ subunit (Gearing et al., 1992; Davis et al., 1993; Yang, 1993; Pennica et al., 1995). CNTF receptor signaling is initiated by binding to a unique $\alpha$ component that results in subunit oligomerization and activation of an associated Jak tyrosine kinase (Ip et al., 1993; Boulton et al., 1994). Jaks induce phosphorylation of tyrosine residues on the receptor that then selectively bind cytoplasmic proteins including signal transducers and activators of transcription, STATs (Ihle, 1996). In chick ciliary ganglia, CNTF induces the tyrosine phosphorylation primarily of STAT3 (Wishingrad et al., 1997).

CNTF also has survival activity for motor, sensory, sympathetic, and hippocampal neurons, regulates nicotinic acetylcholine receptors on autonomic neurons, and regulates neurotransmitter expression in sympathetic and central neurons (Halvorsen and Berg, 1989; Oppenheim et al., 1991; Ip and Yancopoulos, 1994; Lewis et al., 1994; Sendtner et al., 1994; Sun et al., 1994). CNTF and LIF may have important effects on skeletal neuromuscular junction development, maintenance, and regeneration (English and Schwartz, 1995; Ip et al., 1995; Li et al., 1995; Stoop and Poo, 1995; Jordan, 1996; Pennica et al., 1996; Kurek et al., 1997). CNTF-related cytokines also affect cardiac development. Chick cardiac muscle expresses CNTF activity and CNTF receptor mRNA during embryogenesis (Collins, 1985; Wang and Halvorsen, 1998). In rat ventricular cells, cardiotrophin-1, LIF, and, to a much lesser extent, CNTF induce hypertrophy, promote survival, and stimulate immediate-early gene expression (Wollert et al., 1996; Sheng et al., 1997). Null mutations in the gp130 gene 
result in ventricular hypoplasia, whereas gain-of-function gp130 mutants exhibit ventricular hypertrophy (Hirota et al., 1995; Yoshida et al., 1996).

In embryonic chick atria, functional coupling of vagal stimulation to inhibition of heart rate develops from embryonic day 10 (E10) to E12 and is mediated by acetylcholine acting on muscarinic receptors to open $\mathrm{K}^{+}$channels in the sinoatrial node (Pappano and Löffelholz, 1974). Here we report that CNTF receptors are expressed on embryonic cardiomyocytes and that peak levels correspond with the appearance of functional parasympathetic innervation of the atrium. Furthermore, we show that CNTF receptor level is enhanced by muscarinic cholinergic activity in ovo and that CNTF upregulates muscarinic receptors in cultured atrial myocytes.

\section{MATERIALS AND METHODS}

Cell culture. Enriched cultures of atrial and ventricular myocytes were prepared from 8- to 9-d-old chick embryos by preplating to remove nonmyocytes and were used after 3-4 d of incubation as described previously (Hunter and Nathanson, 1986; Lu and Halvorsen, 1997). This preplating procedure removes $\sim 95 \%$ of fibroblasts from the cell suspension (Galper et al., 1984). Chick ciliary ganglion neurons were cultured from E8 embryos in medium supplemented with $25 \mathrm{mM} \mathrm{KCl}$ to provide for cell survival as described previously (Koshlukova et al., 1996).

$R N A$ preparation and Northern blots. Total RNA was isolated by a single-step method using guanidinium thiocyanate-phenol-chloroform extraction (Chomczynski and Sacchi, 1987), and poly $\left(\mathrm{A}^{+}\right)$mRNA was collected through one passage over oligo-dT cellulose columns. Total RNA (20 $\mu \mathrm{g} /$ lane) or poly( $\left.\mathrm{A}^{+}\right)$RNA (10 $\mu \mathrm{g} /$ lane) was separated on an $0.8 \%$ agarose gel containing $6.3 \%$ formaldehyde. Northern blot analysis was performed using $5 \times 10^{6} \mathrm{cpm} / \mathrm{ml}$ of an $\left[\alpha-{ }^{32} \mathrm{P}\right] \mathrm{dATP}-l a b e l e d 269$ nucleotide chick CNTF (GPA) probe (Leung et al., 1992) or a 571 nucleotide CNTF receptor $\alpha$ probe (Heller et al., 1995; Wang and Halvorsen, 1998). After hybridization at $42^{\circ} \mathrm{C}$ for $16 \mathrm{hr}$ and highstringency washing at $65^{\circ} \mathrm{C}$, the blots were exposed to Kodak X-omat film. As an internal control, the blots were stripped and then hybridized with a ribosomal L-27 probe following the same procedure (Lebeau et al., 1991; Wang and Halvorsen, 1998). Data from the indicated number (n) of experiments are expressed as the mean \pm SEM or range (for $n=$ 2). Data were analyzed using a one-sided Student's $t$ test.

Immunoblot detection. Freshly isolated atria or cardiomyocytes cultured for the indicated time were rinsed and homogenized in PBS. Soluble cytoplasmic proteins were collected after centrifugation to remove particulate material and were dissolved in Laemmli sample buffer. Protein samples were subjected to SDS-PAGE (7.5\% acrylamide) and transferred to nitrocellulose membranes as described previously (Koshlukova et al., 1996; Wishingrad et al., 1997). Immunoblots were assayed first with a polyclonal antibody directed against tyrosine-phosphorylated (Y705) STAT3 (1:1000) and then were stripped and assayed with a monoclonal antibody to STAT3 for normalization. Some blots were probed with an anti-synapsin I antibody (1:5000) or an antineurofilament antibody $(1 \mu \mathrm{g} / \mathrm{ml})$. Antibody-antigen complexes were visualized using enhanced chemiluminescence according to the manufacturer's instructions (Amersham, Arlington Heights, IL). The level of signals was quantitated by scanning densitometry.

Immunocytochemistry. Cardiomyocytes prepared as described above were plated on coverslips, fixed in $4 \%$ paraformaldehyde for $15 \mathrm{~min}$ at room temperature, permeabilized in $0.1 \%$ Triton X-100 in PBS for 5 min, and washed. The cells were then blocked in $5 \%$ bovine serum albumin and PBS for $20 \mathrm{~min}$, incubated with primary antibodies in $5 \%$ bovine serum albumin and PBS for $2 \mathrm{hr}$ at room temperature, and subsequently incubated with rhodamine-labeled secondary antibodies (CappellWorthington, Durham, NC).

Binding assays. Quantitation of muscarinic acetylcholine receptors was performed on a crude membrane preparation from cell cultures using $\left[{ }^{3} \mathrm{H}\right]$ quinuclidinyl benzilate (QNB) as described previously (Halvorsen et al., 1996). Nonspecific binding was determined in the presence of $10 \mu \mathrm{M}$ atropine. Nicotinic acetylcholine receptors were quantified on intact ciliary ganglion neurons using ${ }^{125} \mathrm{I}-\alpha$-bungarotoxin as described previously (Halvorsen and Berg, 1989).

Materials. Embryonated chick eggs (White Leghorn) were obtained from Gawlak Farms (Lawton, NY) and grown at $37^{\circ} \mathrm{C}$ in a humidified incubator. Human recombinant CNTF was provided by Regeneron Pharmaceuticals (Tarrytown, NY), anti-synapsin I antibody was from J. Bixby (University of Miami), and GPA (avian CNTF) was a gift from R. Nishi (Oregon Health Sciences University). Monoclonal anti-STAT3 antibody was from Transduction Laboratories (Lexington, KY), polyclonal anti-phospho-STAT3 antibodies were from New England Biolabs (Beverly, MA), anti-neurofilament monoclonal antibody (145 kDa) was from Oncogene Research Products (Cambridge, MA), goat anti-mouse IgG-HRP was from Amersham, and goat anti-rabbit IgG-HRP was from Amresco (Solon, OH). Sources of other reagents were as described previously (Koshlukova et al., 1996; Malek and Halvorsen, 1997).

\section{RESULTS}

\section{Expression of CNTF receptor $\alpha$ mRNA in heart peaks during the onset of parasympathetic innervation of atria}

We found previously that cultures of embryonic chick heart myocytes express mRNA for the CNTF receptor $\alpha$ subunit (Wang and Halvorsen, 1998). To exclude the possibility that expression of this transcript was induced only as a result of cell culture, we assayed mRNA isolated from atria and ventricles during embryonic development. A single transcript size of $\sim 2.7$ $\mathrm{kb}$ was detected in mRNA from hearts isolated from E3 to E21 embryos as measured by Northern blotting (Fig. $1 A$ ). Expression of CNTF receptor mRNA was four times greater in atria isolated from E11 to E13 embryos compared with that in tissue from E6 embryos. Ventricles showed approximately a twofold increase in CNTF receptor between E6 and E13. In addition, levels in E13 atria were 2.5 times greater in atria than in ventricles (Fig. 1 $A$ ). This developmental profile was different from that observed for skeletal muscle in which expression levels were stable from E6 to E13 and then declined to $\sim 60 \%$ of that level by E21 (Fig. $1 B$ ). Expression of CNTF receptor in ciliary ganglia showed a profile qualitatively similar to that in heart, but the peak at E11 was only 1.6 times that of E6 (Fig. $1 B$ ). Thus, heart CNTF receptor mRNA exhibited both temporal and spatial regulation during cardiac development.

\section{Expression of functional CNTF receptors on atrial myocytes}

Because the known CNTF receptor is composed of at least two subunits in addition to $\mathrm{CNTF}$ receptor $\alpha$, we determined whether heart expresses functional CNTF receptors coupled to the Jak and STAT signal transduction pathway. Atria were freshly isolated and placed in an organ bath before treatment with CNTF. Atria stimulated with CNTF showed an increase in tyrosine phosphorylation of the transcription factor STAT3 as detected by immunoblotting with an antibody specific to phosphorylated (Y705) STAT3 (Fig. 2A).

Atrial tissue includes several cell types including cardiac fibroblasts, cardiomyocytes, and parasympathetic cardiac ganglia. To determine which cells expressed functional CNTF receptors, we prepared primary cultures highly enriched in myocytes by preplating the dissociated cells to remove fibroblasts. No neurons were observed in these cardiomyocyte cultures, and no reactivity with anti-synapsin I (Fig. 2E) or anti-neurofilament (data not shown) antibodies was detected on immunoblots. Cultures of atrial myocytes treated with either human CNTF or chicken CNTF (GPA) also showed an increase in phospho-STAT3 (Fig. $2 B)$. Experiments performed with cultures of chick ventricle myocytes gave results similar to that of experiments with atrial myocytes except that ventricular cells required higher concentrations of CNTF to elicit equivalent phospho-STAT3 responses (data not shown). The response to CNTF of the cultured fibro- 


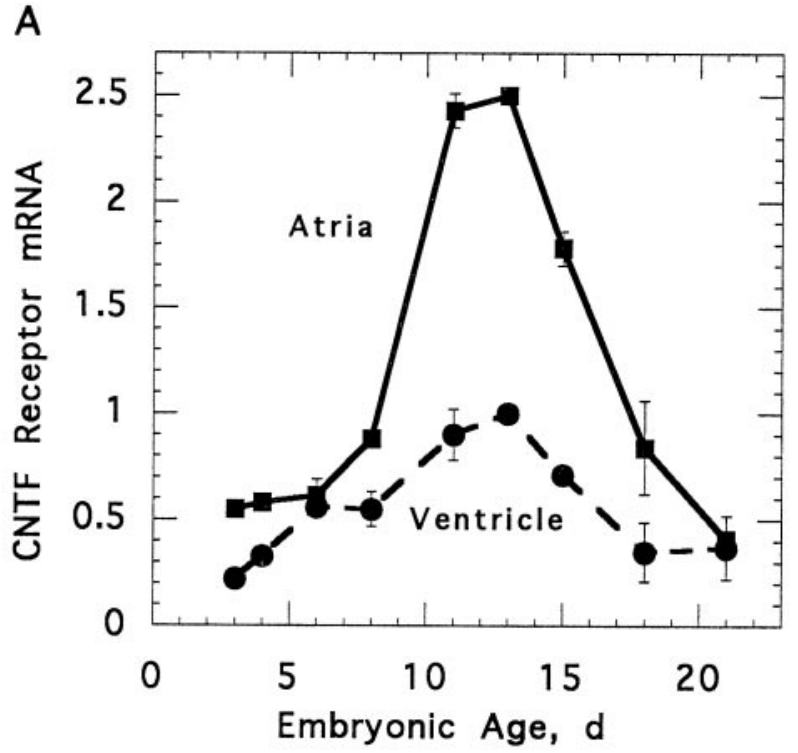

$\begin{array}{llllllllll}\text { Age } & 3 & 4 & 6 & 8 & 11 & 13 & 15 & 18 & 21\end{array}$

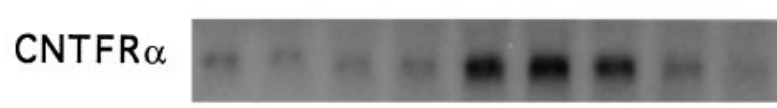

L27

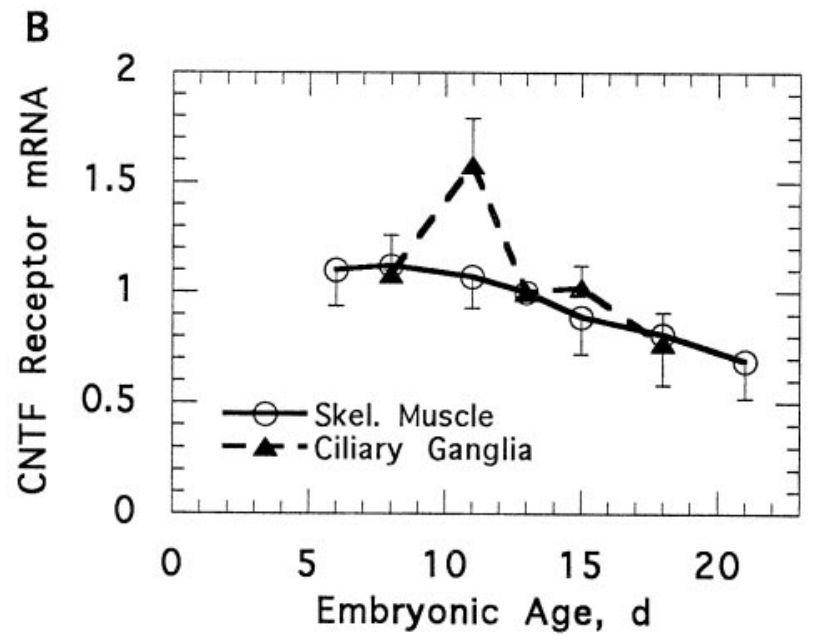

Figure 1. Peak expression of CNTF receptor $\alpha$ mRNA at E11-E13 in developing chick atria. Tissues were isolated from chick embryos of the indicated age and processed for Northern analysis of CNTF receptor $\alpha$ and L27 mRNAs as described in Materials and Methods. A, Top, Relative amounts of CNTF receptor $\alpha$ mRNA from atria (filled square) and ventricles (filled circle) plotted after levels were normalized to the signal detected in E13 ventricle preparations. The results are the means of two determinations ( \pm range) for all ages except for E3 and E4 in which $n=$ 1. A, Bottom, Representative result comparing CNTF receptor $(C N T F R \alpha)$ and L27 mRNA signals from atria of the indicated ages. At E13, atria expressed 2.5 times more CNTF receptor $\alpha$ mRNA than did ventricles. $B$, Relative amounts of CNTF receptor $\alpha$ mRNA from skeletal muscle (open circle) and ciliary ganglia (filled triangle) plotted after levels were normalized to the signal detected from each tissue at E13. The results are the mean of two determinations ( \pm range) for skeletal muscle and the mean of three determinations $( \pm$ SEM) for ciliary ganglia. A direct comparison indicated that E13 skeletal muscle expressed four times as much CNTF receptor mRNA as did E13 atria $(n=2)$. blasts from the preplating step was attenuated several fold compared with the response of the myocytes and probably reflected the carryover of some cardiomyocytes into the fibroblast preparation (Fig. 2D). Additionally, fibroblasts isolated during this procedure showed negligible levels of CNTF receptor mRNA compared with atrial myocytes, supporting the conclusion that it was the myocyte population and not fibroblasts that express CNTF receptors.

To confirm that CNTF was activating STAT3 in cardiomyocytes, we tested for nuclear translocation of phospho-STAT3 using fluorescence microscopy. Untreated myocytes showed a diffuse distribution of STAT3 in the cytoplasm, whereas cells treated for 15 min with CNTF demonstrated a nuclear accumulation of the protein (Fig. 3). Overall, $\sim 35 \%$ of the myocytes showed a clearly detectable nuclear STAT3 signal after CNTF treatment, whereas untreated cells never showed nuclear STAT3. The response was not seen in all cells, perhaps because the atria were isolated from E9 embryos, which have a relatively low expression of CNTF receptor mRNA. These data show that atrial myocytes express functional receptors that couple CNTF binding to the Jak and STAT signaling pathway.

Some reports suggest that CNTF at higher concentrations may activate the LIF receptor in the absence of CNTF receptor $\alpha$ (Gearing et al., 1994). Because the chick CNTF receptor $\alpha$ is attached to the extracellular membrane by a glycosylphosphatidylinositol bond (Heller et al., 1995; Ip et al., 1995; Koshlukova et al., 1996), we determined whether the CNTF response was still present after treatment with a phosphatidylinositol-specific phospholipase C. Exposure of cells to phosphatidylinositol-specific phospholipase $\mathrm{C}$ resulted in a $>90 \%$ decrease in the CNTF-induced tyrosine phosphorylation of STAT3 (Fig. 2C), a result consistent with CNTF acting via the glycosyl-phosphatidylinositol-linked CNTF receptor $\alpha$ subunit.

The level of CNTF receptor $\alpha$ subunit mRNA correlates with the degree of response of cells to CNTF. A comparison of the CNTF sensitivity of atrial tissues between E8 and E11 embryos showed that E11 atria responded with a significantly greater STAT3 response than did E8 atria (Fig. 4). In this assay, atria from E8 embryos were relatively insensitive to CNTF at concentrations of $10 \mathrm{pm}$ or lower, whereas atria from E11 embryos showed a significant response to 1 pM CNTF (Fig. 4). After we take into account that these atria represent intact tissue and that atrial CNTF receptor mRNA levels are $\sim 10$-fold lower, this level of sensitivity to CNTF agrees well with that predicted from earlier results from cultured ciliary ganglion neurons that revealed a half-maximal survival response to $\mathrm{CNTF}$ of $\sim 1 \mathrm{pm}$ (Koshlukova et al., 1996). Furthermore, these data are consistent with our previous results showing a good correlation between CNTF receptor $\alpha$ mRNA levels, CNTF receptor numbers, and CNTF sensitivity in cultured ciliary ganglion neurons and in SH-SY5Y neuroblastoma cells (Malek and Halvorsen, 1997; Wang and Halvorsen, 1998). Thus, the increased expression of CNTF receptor mRNA at E11 was accompanied by an increased responsiveness of these atria.

\section{Chick heart extracts contain CNTF mRNA and CNTF-like bioactivity}

For the presence of CNTF receptors on cardiomyocytes to be functionally relevant, there must be a source of CNTF in the embryonic heart. Soluble extracts from embryonic hearts were 
A

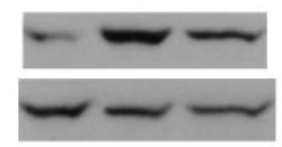

Ctrl GPA CNTF
B

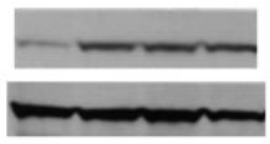

Ctrl GPA CNTF $5 \quad 10$
C

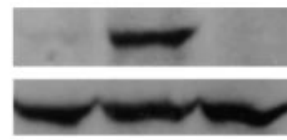

Ctrl CNTF PLC + CNTF

\section{PY-STAT3}

STAT3

E
D

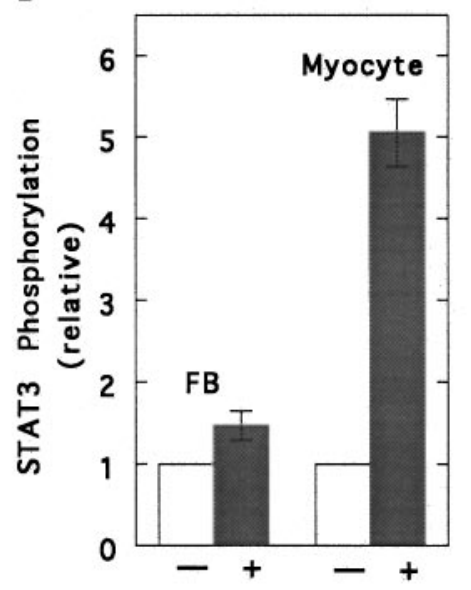

Myo FB CG

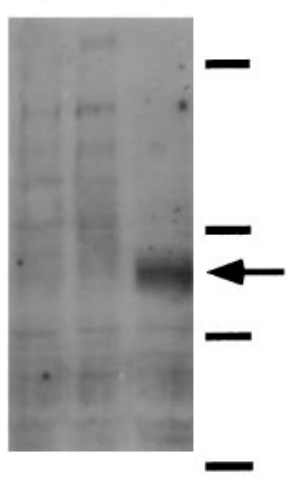

Figure 2. CNTF stimulates the tyrosine phosphorylation of STAT3 in atrial cells. $A, B$, Intact $\mathrm{E} 9$ atria were treated with CNTF (2 nM) or GPA (2 nM) for $20 \min (A)$, and cultured $\mathrm{E} 9$ atrial myocytes were treated with CNTF (2 nM) for 10 min or GPA (2 nM) for 5 or $10 \mathrm{~min}(B)$. Cell lysates were subjected to immunoblot analysis with an anti-phospho-STAT3 antibody ( $P Y$ STAT3; upper rows). Blots were subsequently stripped and reprobed with an anti-STAT3 antibody (STAT3; lower rows) for normalization of protein levels. Similar results were observed in five to six independent experiments. $C$, Cultured atrial myocytes were untreated or exposed to phosphatidylinositol-specific phospholipase $\mathrm{C}(P L C)$ for $50 \mathrm{~min}$ before stimulating with CNTF (1 nM) for $10 \mathrm{~min}$. Cell lysates were processed for phospho-STAT3 and STAT3 levels as described in $A$. Similar results were observed in two additional experiments. $D$, Enriched cultures of cardiac fibroblasts ( $F B$; from the preplating step, left columns) and atrial myocytes (after preplating, right columns) were prepared as described in Materials and Methods and were tested for CNTF-induced STAT3 tyrosine phosphorylation. Cells were untreated (-; open bars) or treated with CNTF (2 nM; +; shaded bars) for 10 min, and cell lysates were subjected to immunoblot analysis for STAT3 tyrosine phosphorylation with the anti-phospho-STAT3 antibody and the anti-STAT3 antibody. The results were quantified and presented as the mean $( \pm$ SEM; $n=3$ ) of the ratios of phosphotyrosine-STAT3 to STAT3 signals in CNTF-treated cells normalized to the signal from untreated cells. E, Immunoblot of cell lysates from cultures of atrial fibroblasts $(F B)$, atrial myocytes $(M y o)$, and ciliary ganglion neurons $(C G)$ was probed with anti-synapsin I antibody. The arrow indicates the position of synapsin $(\sim 84 \mathrm{kDa})$ that is present in neural cultures but not discernible in fibroblast or muscle cultures ( $n=3$ determinations). Horizontal bars indicate the positions of molecular weight standards of 200, 97.4, 68, and $43 \mathrm{kDa}$, from top to bottom, respectively. A similar pattern of expression was obtained using an anti-neurofilament antibody (data not shown). used as a source of putative CNTF-containing 20-25 kDa material and were tested on cultured ciliary ganglion neurons for stimulation of cell growth and regulation of $\alpha$-bungarotoxinbinding nicotinic acetylcholine receptors (Halvorsen and Berg, 1989; Koshlukova et al., 1996). These effects are much more specific for CNTF on ciliary ganglion neurons than is assessing cell survival (Halvorsen and Berg, 1989; Eckenstein et al., 1990). Treatment of ciliary ganglion neurons with heart extracts produced an increase in cell growth and a downregulation of ${ }^{125} \mathrm{I}-\alpha$ bungarotoxin binding (Fig. $5 A$ ). The effects of heart extract were similar to those of chick eye-derived CNTF, and when the two components were used in combination, the effects were not additive. At maximal concentrations, the response of the heartderived CNTF activity on nicotinic receptor levels was the same as that of eye CNTF (Fig. $5 B$ ). Thus, extracts prepared from embryonic chick heart contain CNTF-like bioactivity.

To determine whether CNTF is produced in the heart, we assayed for expression of avian CNTF mRNA using Northern analysis. A single band of $\sim 1.6 \mathrm{~kb}$ was detected in Northern blots of mRNA from embryonic atria and eye, and densitometric analysis revealed that atria expressed $\sim 10 \%$ of the level expressed in eyes (Fig. 6A). The developmental profile of CNTF mRNA in chick heart produced a pattern similar to that seen for CNTF receptor $\alpha$ mRNA. Levels in atria from E11 embryos were $\sim 25 \%$ greater than those from E8 embryos, and E11 atria expressed approximately twice the amount seen in E11 ventricles (Fig. 6B).
The magnitude of the increase from E8 to E11 in CNTF mRNA was much less than that seen for CNTF receptor mRNA, but the difference between atrial and ventricular expression was similar for both CNTF and its receptor.

\section{Muscarinic acetylcholine receptor activity upregulates atrial CNTF receptor $\mathrm{MRNA}$ in vivo}

The developmental profiles of the expression of CNTF and CNTF receptor mRNAs revealed a correlation with the maturation of parasympathetic synapses in the atria (Pappano and Löffelholz, 1974). To determine whether the increase in CNTF receptor mRNA is dependent on activity at developing cholinergic synapses in the heart, we treated embryos with the muscarinic acetylcholine receptor agonist carbachol to mimic parasympathetic activity or with the muscarinic receptor antagonist atropine to prevent the effects of cholinergic activity. Treatment of E9 embryos with carbachol for just $8 \mathrm{hr}$ resulted in an additional $24 \%$ increase in atrial CNTF receptor mRNA compared with that in embryos allowed to develop normally (Fig. 7). Blockade of muscarinic receptors with atropine between E9 and E11 resulted in atrial CNTF receptor levels that were $60 \%$ of those seen in untreated embryos (Fig. 7). This represented an inhibition of nearly $50 \%$ of the expected developmental increase over this period. Therefore, expression of CNTF receptor mRNA in atria was regulated by muscarinic receptor activity. 

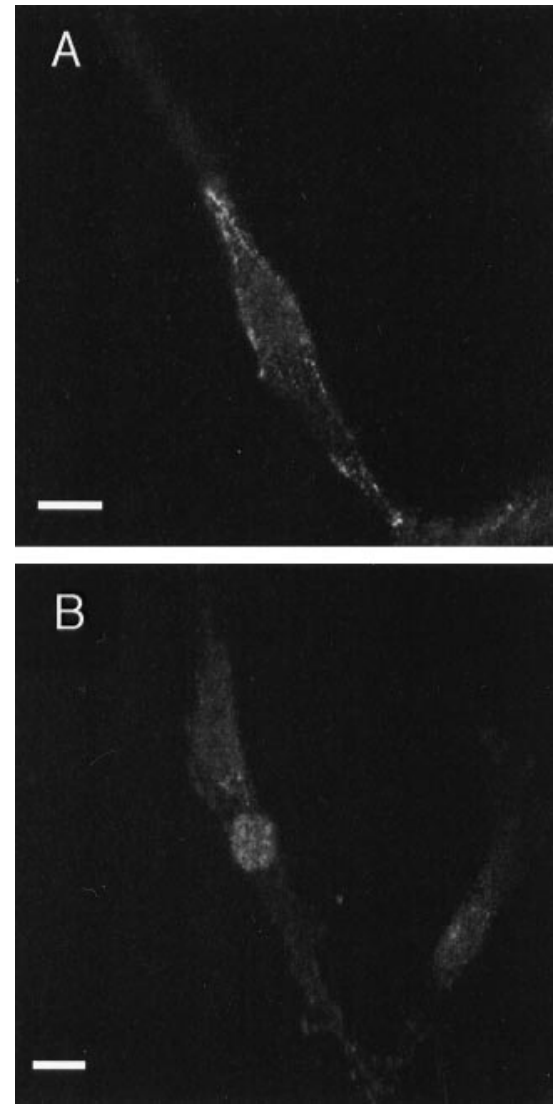

Figure 3. Nuclear accumulation of phospho-STAT3 in CNTF-treated atrial myocytes. Cultured atrial myocytes from E9 embryos were treated $(B)$ or untreated $(A)$ for 15 min with CNTF $(2 \mathrm{nM})$. Cells were fixed, probed with an anti-phospho-STAT3 antibody and the rhodamineconjugated secondary antibody, and imaged by confocal fluorescence microscopy. The STAT3 signal was extranuclear in the absence of CNTF and concentrated in nuclei after CNTF treatment. Scale bars, $10 \mu \mathrm{m}$.

\section{CNTF regulates muscarinic receptor levels in cultured atrial myocytes}

Previous reports suggest that CNTF may play a role in the development or maintenance of skeletal neuromuscular junctions (Stoop and Poo, 1995; Jordan, 1996). These results, coupled with ours indicating that muscarinic receptor activity regulates CNTF receptor expression, suggested that CNTF may affect parasympathetic synaptic components in the heart. Therefore, we tested for the effects of CNTF on cultured cells because the efficiency of CNTF absorption across the chorioallantoic membrane and into embryos has not been determined. Treatment of cultured E9 atrial myocytes with CNTF for $24 \mathrm{hr}$ resulted in a concentrationdependent increase of up to twofold in muscarinic receptor levels (Fig. 8). CNTF treatment of ventricular myocytes, which have less CNTF receptor mRNA and a diminished Jak and STAT response, resulted in no significant change in muscarinic receptor number (Fig. 8). Control experiments performed on cultured cardiac fibroblasts detected an insignificant number of muscarinic receptors, with or without CNTF treatment (Fig. 8). Thus, CNTF treatment of atrial myocytes resulted in an increased number of muscarinic receptors, the principal site of action of acetylcholine on heart cells.

\section{DISCUSSION}

Two key questions pertaining to cytokine neurobiology are addressed in this report. One is how cells regulate their response to

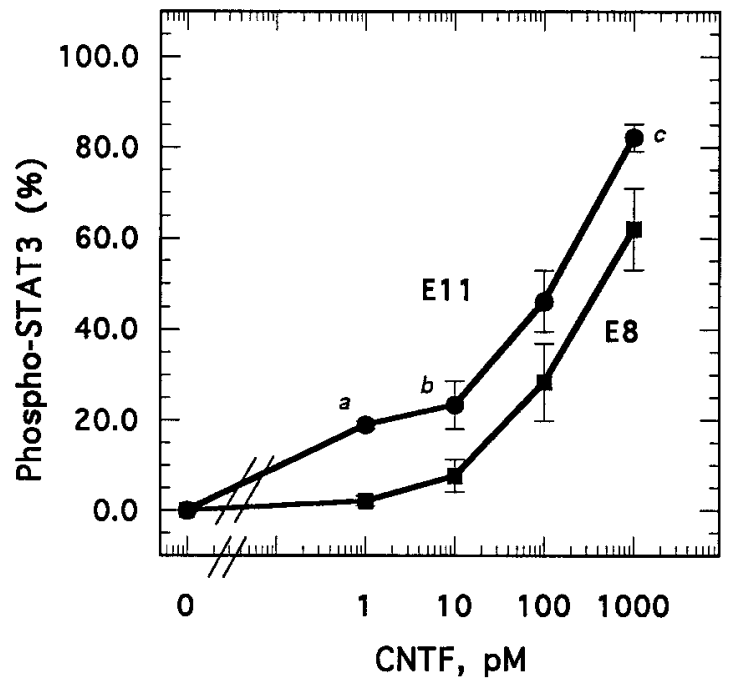

Figure 4. Atria from E11 embryos show an enhanced CNTF response over that from E8 atria. Atria were isolated from E8 or E11 embryos and placed in an organ bath. Atria were exposed to the indicated concentration of CNTF for 20 min before tissue lysates were analyzed by Western blotting. The ratios of phosphotyrosine-STAT3 to STAT3 signals were calculated and plotted as a percent (mean \pm SEM; $n=3-7$ ) of the maximum level observed in each experiment; $a, p<0.0005 ; b, p<0.025$; and $c, p<0.05$, each compared with the E8 response by Student's $t$ test.

individual cytokines during specific stages of development. The second is the role(s) of neurokine receptors that are expressed on target cells of the nervous system. The physiological role(s) of CNTF-like cytokines in the development and maintenance of the vertebrate nervous system is still being elucidated, but they have dramatic effects on a variety of neuronal and glia cell types. Here, we have described a critical period of CNTF receptor expression in the developing chick heart that seems to impart on atrial myocytes a brief window of increased sensitivity to CNTF regulation of muscarinic acetylcholine receptor number. At the same time, activity of muscarinic receptors at maturing parasympathetic synapses in atria is a key regulator of CNTF receptor expression.

\section{Parasympathetic innervation and expression of CNTF receptors in the developing chick heart}

We found that the expression of CNTF and CNTF receptor $\alpha$ subunit mRNA was much higher in atria than in ventricles and peaked at E11-E13. This corresponds to the time during which functional parasympathetic synapses are forming on sinoatrial node cells in the chick (Pappano and Löffelholz, 1974). Morphological signs of impending parasympathetic innervation appear even earlier as vagal fibers extend throughout the atria from E5 to E7 (see Pappano, 1977) and cardiac ganglia are observed in atria as early as E7-E8 (Rickenbacher and Müller, 1979). A more precise correlation of timing between synapse formation and CNTF receptor expression must await a careful analysis of the appearance of synaptic function and synapse-specific markers. In the chick, more so than in mammals, parasympathetic innervation of ventricles is also evident, but this occurs to a lesser extent than in atria (see Löffelholz and Pappano, 1985). Our data support a role for this emerging cholinergic activity in the regulation of CNTF receptors. Stimulation of muscarinic acetylcholine receptors in ovo with carbachol caused a $24 \%$ increase in CNTF receptor expression compared with that in untreated embryos. This resulted in a doubling of the rate of accumulation of CNTF 
A

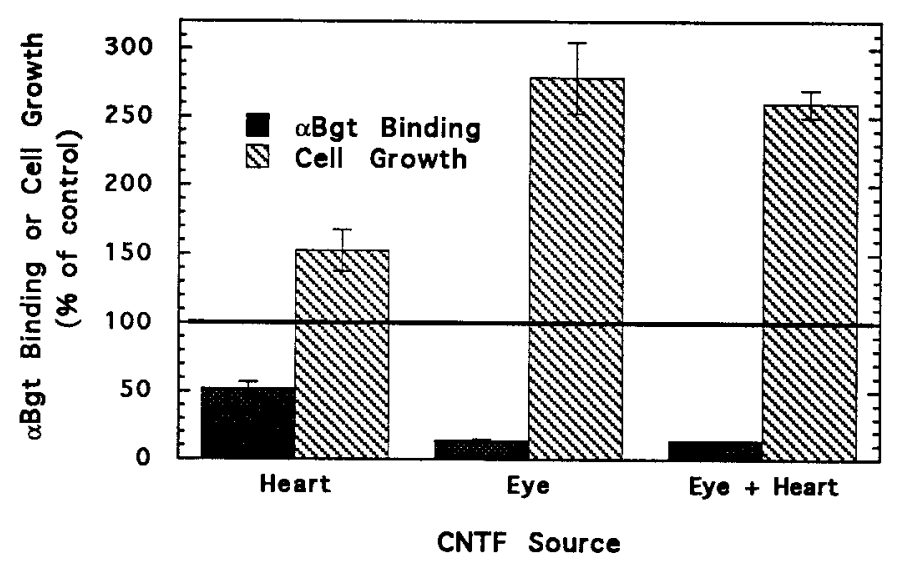

B

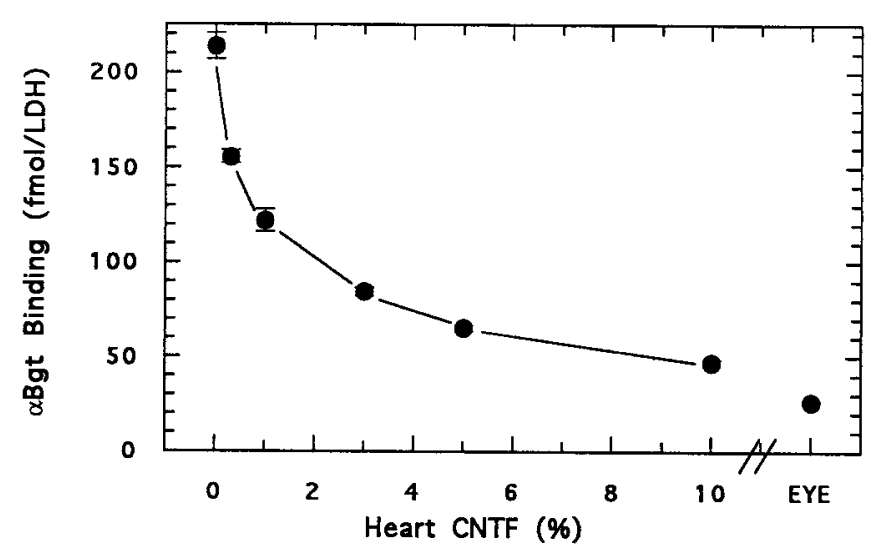

Figure 5. Embryonic chick heart contains CNTF-like bioactive components. Soluble extracts from E15 hearts were passed over a sizing column, and $25 \mathrm{kDa}$ components were pooled, producing a partially purified preparation of CNTF (Halvorsen and Berg, 1989). A, A heart CNTF pool $(3 \% \mathrm{v} / \mathrm{v} ; 2.7 \mu \mathrm{g}$ of protein $/ \mathrm{ml}$ of final $\mathrm{ml}$ of final solution) and chick eye CNTF pool were tested for activity for $3 \mathrm{~d}$ on cultured E8 ciliary ganglion neurons by measuring cellular lactate dehydrogenase (LDH) activity (for growth) and levels of ${ }^{125} \mathrm{I}-\alpha$-bungarotoxin $(\alpha B g t)$ binding. The effects of heart and eye CNTF were not additive. Results are means \pm range for $n=2$ experiments. $B$, The medium for E8 ciliary ganglion neurons was supplemented with the indicated final concentration $(\mathrm{v} / \mathrm{v})$ of the heart CNTF pool or the eye CNTF pool $(3 \% \mathrm{v} / \mathrm{v})$ for $3 \mathrm{~d}$. Specific ${ }^{125} \mathrm{I}-\alpha-$ bungarotoxin binding was performed, and the results were normalized to cellular LDH activity. At maximal concentrations (10\%), the magnitude of heart CNTF effects was similar to that of eye CNTF. The results are from a single experiment performed in triplicate (mean \pm SEM).

receptor mRNA from $2.4 \%$ per hour in normal embryos to over $5 \%$ per hour in the presence of carbachol. Furthermore, inhibition of muscarinic receptors with atropine prevented nearly half of the normal developmental increase between E9 and E11. It is unclear, however, whether all of the in vivo increases of CNTF receptors can be accounted for by muscarinic receptor activity. The failure of atropine to prevent completely the increase in CNTF receptor may be because some effects of acetylcholine have been initiated by E9. But, other neuromodulators, such as ATP and somatostatin, are coreleased with acetylcholine from parasympathetic nerves (Epstein et al., 1988; Brodde and Zerkowski, 1994) and may also influence CNTF receptor expression.
A
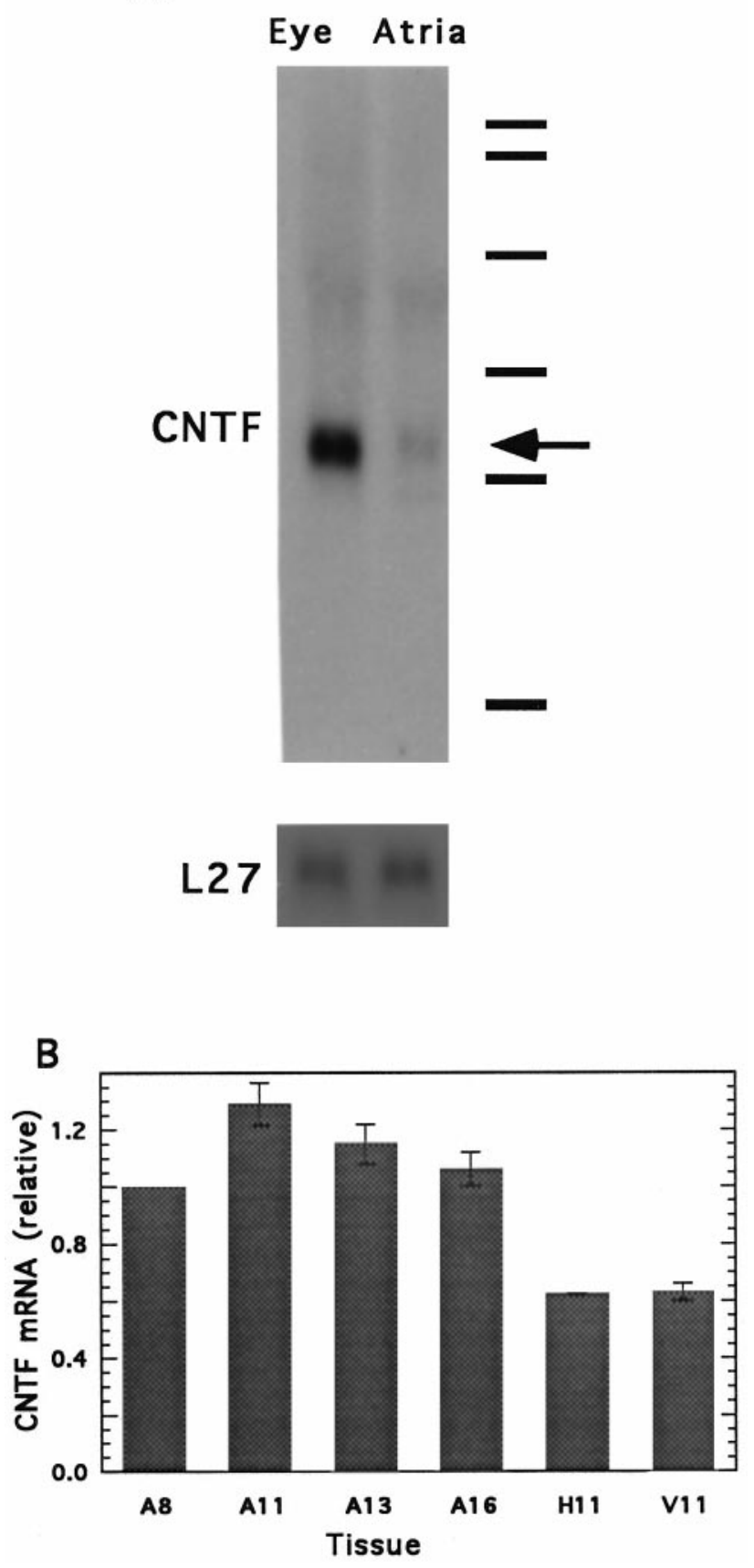

Figure 6. Expression of avian CNTF mRNA peaks at E11 in embryonic atria. $A$, Northern blot hybridization of an $\left[\alpha^{-3} \mathrm{P}\right] \mathrm{dATP}$-labeled probe for chick CNTF mRNA detected an $\sim 1.6 \mathrm{~kb}$ species (arrow) in poly $\left(\mathrm{A}^{+}\right)$ RNA prepared from E11 atria and eyes. Horizontal bars indicate RNA molecular size markers (BRL) of 9.49, 7.46, 4.40, 2.37, 1.35, and $0.24 \mathrm{~kb}$ from top to bottom, respectively. $B$, Poly $\left(\mathrm{A}^{+}\right)$RNA was isolated from E8, $\mathrm{E} 11, \mathrm{E} 13$, and E16 atria $(A)$ and from E11 heart $(H)$ and ventricle $(V)$ and subjected to Northern analysis. Results were quantified by phosphoimaging, normalized to control L27 mRNA levels, and plotted relative to the CNTF to L27 ratio of E8 atria. The results are the mean ( \pm range) of two independent experiments.

During the period when CNTF receptor expression increased nearly fourfold in atrial muscle, levels showed a gradual decline in skeletal muscle; thus the increase in heart was not a general feature of chick development. Interestingly, CNTF receptor lev- 


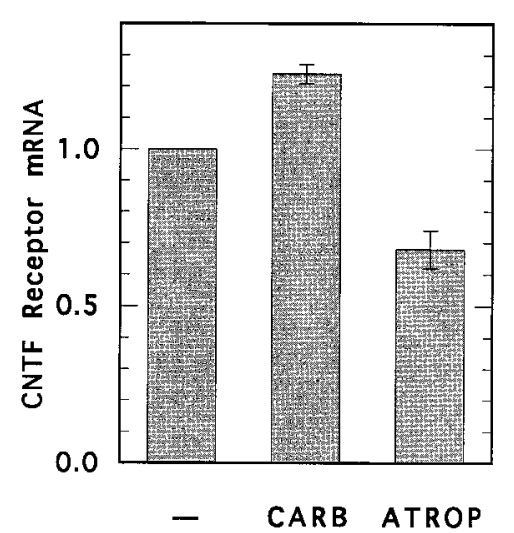

TREATMENT

Figure 7. Muscarinic acetylcholine receptor activity regulates CNTF receptor $\alpha$ mRNA. Embryos were untreated (-) or treated on day 9 with carbachol $(C A R B ; 2 \mu \mathrm{mol})$ for $8 \mathrm{hr}$ or atropine $(A T R O P ; 0.1 \mu \mathrm{mol})$ for 48 hr. Atrial mRNA was isolated and subjected to Northern analysis using the CNTF receptor $\alpha$ probe followed by the L27 probe for normalization. The results are means expressed relative to results from untreated embryos of the same age and are from two and three independent experiments for carbachol- and atropine-treated embryos, respectively.

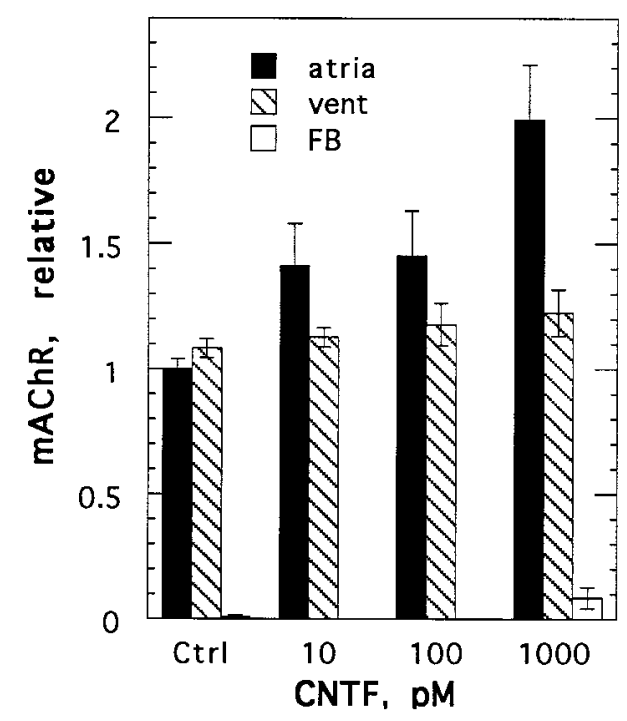

Figure 8. CNTF regulates muscarinic receptor levels in cultured atrial myocytes. Atrial myocytes (filled bars), ventricular myocytes (vent; hatched bars), and cardiac fibroblasts (FB; open bars) were cultured in the absence $(\mathrm{Ctrl})$ or presence of the indicated concentration of CNTF for 24 hr. Note that fibroblasts were tested only with 0 or 1000 pM CNTF. Muscarinic acetylcholine receptor $(m A C h R)$ levels were determined from specific $\left[{ }^{3} \mathrm{H}\right] \mathrm{QNB}$ binding to cell lysates and were normalized to cellular protein. Results are mean \pm SEM (or range) from two to three independent determinations expressed relative to that in untreated atrial cell cultures.

els in the parasympathetic chick ciliary ganglia showed a peak coinciding with that in heart. This is also the period during which chick ciliary ganglion neurons are consolidating synapses in their targets in the eye; thus it may be that CNTF receptors play both a pre- and postsynaptic role in cholinergic synapse formation.

\section{Role of CNTF receptors on developing myocytes}

Cardiomyocytes have functional CNTF receptors that stimulate the tyrosine phosphorylation of STAT3 and result in its cytosol- to-nuclear translocation. This is a hallmark of functional CNTF receptor activation in all tissues studied to date but had not been documented previously in cardiomyocytes, although LIF was shown to activate the Jak and STAT pathway in rat cardiac myocytes (Kunisada et al., 1996). CNTF stimulation of STAT3 was observed in cultured myocytes as well as in freshly isolated atria. This result, combined with our finding that embryonic chick heart expressed avian CNTF, indicates that under these conditions CNTF receptors are not maximally activated by CNTF in atria and suggests that regulating the levels of CNTF and/or its receptors will affect cellular responsiveness. An important effect of CNTF on cultured atrial myocytes was the upregulation of acetylcholine receptors, a main determinant of parasympathetic effects in the heart. This effect of CNTF was not observed in cultured ventricular myocytes and suggests a correlation with the normal developmental increase in chick atrial muscarinic receptors that coincides with parasympathetic innervation. Expression of muscarinic receptors in embryonic chick atria, but not ventricles, was shown previously to increase by $30 \%$ to $60 \%$ between E10 and E15 (Kirby and Aronstam, 1983; Luetje et al., 1987). Furthermore, the developmental increase was prevented by administration of the muscarinic antagonist atropine (Kirby and Aronstam, 1983). Our results are consistent with CNTF mediating this developmental increase in muscarinic receptor levels in atria in response to increased CNTF receptor levels.

The mechanism of the CNTF regulation of muscarinic receptors has not been determined. Rosoff et al. (1996) have mapped a region of the promoter for the chick $\mathrm{m} 2$ acetylcholine receptor gene that is sensitive to CNTF and LIF when transfected in a reporter construct into nerve cells but, interestingly, not into heart cells. Our results suggest that the absence of detectable CNTF effects on muscarinic acetylcholine receptor levels in their study was likely attributable to the preponderance of ventricular myocytes in cultures derived from total chick heart (Rosoff et al., 1996). The question of why ventricles lack this CNTF response is intriguing. Although CNTF elicits tyrosine phosphorylation of STAT3 in ventricular myocytes (X. Wang and S. W. Halvorsen, unpublished observations), the response requires much greater concentrations of CNTF than is required in atrial myocytes, perhaps because of the lowered level of CNTF receptor expression in ventricles. However, it is possible that CNTF activation of STAT3 is not the primary means of muscarinic receptor regulation and that alternative CNTF-activated pathways may be required. The coupling of CNTF receptors to these pathways may be limiting in ventricular myocytes.

\section{A model for parasympathetic synapse formation}

These results offer a model for parasympathetic synapse formation that involves a coordination of pre- and postsynaptic actions. Neurites growing through the atria would release small amounts of acetylcholine that is sensed by myocytes. Myocytes respond by increasing the expression of CNTF receptors (and possibly CNTF) that has an autocrine action to increase muscarinic receptor levels further and to enhance muscle and pacemaker responses to parasympathetic nerve activity.

This effect of CNTF on cardiac muscle seems to be different from the effects reported for skeletal muscle. In skeletal muscle, CNTF reduces denervation-mediated muscle atrophy (Helgren et al., 1994) and helps maintain polyneural innervation of muscle fibers (English and Schwartz, 1995; Kwon et al., 1995; Jordan, 1996), responses that are intimately associated with the unique physiology of skeletal muscle compared with cardiac muscle. 
CNTF also produces presynaptic effects on motor neurons at neuromuscular junctions where it is a survival molecule for developing motor neurons in rat (Oppenheim et al., 1991) and potentiates acetylcholine release at developing nerve-muscle synapses in Xenopus cell cultures (Stoop and Poo, 1995). Either of these presynaptic effects could be relevant to parasympathetic neurons in the heart. Parasympathetic neurons are exquisitely sensitive to the survival effects of CNTF in culture, and a stimulation of acetylcholine release at parasympathetic nerve endings would facilitate further the effects of nerve activity on developing atrial myocytes.

\section{REFERENCES}

Adler R, Landa K, Manthorpe M, Varon S (1979) Cholinergic neurotrophic factors: intraocular distribution of soluble trophic activity for ciliary neurons. Science 204:1434-1436.

Boulton TG, Stahl N, Yancopoulos GD (1994) Ciliary neurotrophic factor/leukemia inhibitory factor/interleukin-6/oncostatin-M family of cytokines induces tyrosine phosphorylation of a common set of proteins overlapping those induced by other cytokines and growth factors. J Biol Chem 269:11648-11655.

Brodde O-E, Zerkowski H-R (1994) Neural control of cardiac myocyte function. In: Neurocardiology (Armour JA, Ardell JL, eds), pp 193218. New York: Oxford UP.

Chomczynski P, Sacchi N (1987) Single-step method of RNA isolation by acid guanidinium thiocyanate-phenol-chloroform extraction. Anal Biochem 162:156-159.

Collins F (1985) Electrophoretic similarity of the ciliary ganglion survival factors from different tissues and species. Dev Biol 109:255-258.

Davis S, Aldrich T, Stahl N, Ip N, Yancopoulos G (1993) LIFR $\beta$ and gp130 as heterodimerizing signal transducers of the tripartite CNTF receptor. Science 260:1805-1808.

Eckenstein FP, Esch F, Holbert T, Blacher RW, Nishi R (1990) Purification and characterization of a trophic factor for embryonic peripheral neurons: comparison with fibroblast growth factors. Neuron 4:623-631.

English AW, Schwartz G (1995) Both basic fibroblast growth factor and ciliary neurotrophic factor promote the retention of polyneuronal innervation of developing skeletal muscle fibers. Dev Biol 169:57-64.

Epstein ML, Davis JP, Gellman LE, Lamb JR, Dahl JL (1988) Cholinergic neurons of the chicken ciliary ganglion contain somatostatin. Neuroscience 25:1053-1060.

Fann MJ, Patterson PH (1994) Neuropoietic cytokines and activin-a differentially regulate the phenotype of cultured sympathetic neurons. Proc Natl Acad Sci USA 91:43-47.

Galper JB, Dziekan LC, Smith TW (1984) The development of physiologic responsiveness to muscarinic agonists in chick embryo heart cell cultures. J Biol Chem 259:7382-7390.

Gearing DP, Comeau MR, Friend DJ, Gimpel SD, Thut CJ, McGourty J, Brasher KK, King JA, Gillis S, Mosley B, Ziegler SF, Cosman D (1992) The IL-6 signal transducer, gp130: an oncostatin M receptor and affinity converter for the LIF receptor. Science 255:1434-1437.

Gearing DP, Ziegler SF, Comeau MR, Friend D, Thoma B, Cosman D, Park L, Mosley B (1994) Proliferative responses and binding properties of hematopoietic cells transfected with low-affinity receptors for leukemia inhibitory factor, oncostatin-m, and ciliary neurotrophic factor. Proc Natl Acad Sci USA 91:1119-1123.

Halvorsen SW, Berg DK (1989) Specific down-regulation of the $\alpha$-bungarotoxin binding site on chick autonomic neurons by ciliary neuronotrophic factor. J Neurosci 9:3673-3680.

Halvorsen SW, Malek R, Wang X, Jiang N (1996) Ciliary neurotrophic factor regulates nicotinic acetylcholine receptors on human neuroblastoma cells. Neuropharmacology 35:257-265.

Helgren M, Squinto S, Davis H, Parry D, Boulton T, Heck C, Zhu Y, Yancopoulos G, DiStefano P (1994) Trophic effect of ciliary neurotrophic factor on denervated skeletal muscle. Cell 76:493-504.

Heller S, Finn TP, Huber J, Nishi R, Geiben M, Püschel A, Rohrer H (1995) Analysis of function and expression of the chick GPA receptor $(\mathrm{GPAR} \alpha)$ suggests multiple roles in neuronal development. Development 121:2681-2693.

Hirota H, Yoshida K, Kishimoto T, Taga T (1995) Continuous activation of gp130, a signal-transducing receptor component for interleukin 6-related cytokines, causes myocardial hypertrophy in mice. Proc Natl Acad Sci USA 92:4862-4866.
Hirst GDS, Choate JK, Cousins HM, Edwards FR, Klemm MF (1996) Transmission by post-ganglionic axons of the autonomic nervous system: the importance of the specialized neuroeffector junction. Neuroscience 73:7-23.

Hunter DD, Nathanson NM (1986) Biochemical and physical analyses of newly synthesized muscarinic acetylcholine receptors in cultured embryonic chicken cardiac cells. J Neurosci 6:3739-3748.

Ihle JN (1996) STATs: signal transducers and activators of transcription. Cell 84:331-334.

Ip FCF, Fu AKY, Tsim KWK, Ip NY (1995) Cloning of the $\alpha$ component of the chick ciliary neurotrophic factor receptor: developmental expression and down-regulation in denervated skeletal muscle. J Neurochem 65:2393-2400.

Ip N, Yancopoulos G (1994) Neurotrophic factors and their receptors. Ann Neurol [Suppl] 35:S13-S16.

Ip NY, McClain J, Barrezueta N, Aldrich T, Pan L, Li Y, Wiegand S, Friedman B, Davis S, Yancopoulos G (1993) The $\alpha$ component of the CNTF receptor is required for signaling and defines potential CNTF targets in the adult and during development. Neuron 10:89-102.

Jordan CL (1996) Morphological effects of CNTF treatment during neuromuscular synapse elimination. J Neurobiol 31:29-40.

Kirby ML, Aronstam RS (1983) Atropine-sensitive alterations of normal development of muscarinic receptors in the embryonic chick heart. J Mol Cell Cardiol 15:685-696.

Kishimoto T, Akira S, Taga T (1992) Interleukin-6 and its receptor: a paradigm for cytokines. Science 258:593-597.

Kishimoto T, Taga T, Akira S (1994) Cytokine signal transduction. Cell $76: 253-262$

Koshlukova S, Finn TP, Nishi R, Halvorsen SW (1996) Identification of functional receptors for ciliary neurotrophic factor on chick ciliary ganglion neurons. Neuroscience 72:821-832.

Kunisada K, Hirota H, Fujio Y, Matsui H, Tani Y, Yamauchi-Takihara K, Kishimoto T (1996) Activation of Jak-STAT and MAP kinases by leukemia inhibitory factor through gp130 in cardiac myocytes. Circulation 94:2626-2632.

Kurek JB, Bower JJ, Romanella M, Koentgen F, Murphy M, Austin L (1997) The role of leukemia inhibitory factor in skeletal muscle regeneration. Muscle Nerve 20:815-822.

Kwon YW, Abbondanzo SJ, Stewart CL, Gurney ME (1995) Leukemia inhibitory factor influences the timing of programmed synapse withdrawal from neonatal muscles. J Neurobiol 28:35-50.

Lebeau M-C, Alvarez-Bolado G, Braissant O, Wahli W, Catsicas S (1991) Ribosomal protein L27 is identical in chick and rat. Nucleic Acids Res 19:1337.

Leung DW, Parent AS, Cachianes G, Esch F, Coulombe JN, Nikolich K, Eckenstein FP, Nishi R (1992) Cloning, expression during development, and evidence for release of a trophic factor for ciliary ganglion neurons. Neuron 8:1045-1053.

Lewis SE, Rao MS, Symes AJ, Dauer WT, Fink JS, Landis SC, Hyman SE (1994) Coordinate regulation of choline acetyltransferase, tyrosine hydroxylase, and neuropeptide mRNAs by ciliary neurotrophic factor and leukemia inhibitory factor in cultured sympathetic neurons. J Neurochem 63:429-438.

Li M, Sendtner M, Smith A (1995) Essential function of LIF receptor in motor neurons. Nature 378:724-727.

Lin L-F, Mismer D, Lile J, Armes L, Butler E, Vannice J, Collins F (1989) Purification, cloning, and expression of ciliary neurotrophic factor (CNTF). Science 246:1023-1025.

Löffelholz K, Pappano AJ (1985) The parasympathetic neuroeffector junction of the heart. Pharmacol Rev 37:1-24.

Lu C, Halvorsen SW (1997) Channel activators regulate ATP-sensitive potassium channel (Kir6.1) expression in chick cardiomyocytes. FEBS Lett 412:121-125.

Luetje CW, Gierschik P, Milligan G, Unson C, Spiegel A, Nathanson NM (1987) Tissue-specific regulation of GTP-binding protein and muscarinic acetylcholine receptor levels during cardiac development. Biochemistry 26:4876-4884.

Malek RL, Halvorsen SW (1997) Opposing regulation of ciliary neurotrophic factor receptors on neuroblastoma cells by distinct differentiating agents. J Neurobiol 32:81-94.

Oppenheim R, Prevette D, Qin-Wei Y, Collins F, MacDonald J (1991) Control of embryonic motoneuron survival in vivo by CNTF. Science 251:1616-1618.

Pappano AJ (1977) Ontogenetic development of autonomic neuroeffec- 
tor transmission and transmitter reactivity in embryonic and fetal hearts. Pharmacol Rev 29:3-33.

Pappano AJ, Löffelholz K (1974) Ontogenesis of adrenergic and cholinergic neuroeffector transmission in chick embryo heart. J Pharmacol Exp Ther 191:468-478.

Pennica D, King K, Shaw K, Luis E, Rullamas J, Luoh S-M, Darbonne W, Knutzon D, Yen R, Chien K, Baker J, Wood WI (1995) Expression cloning of cardiotrophin 1, a cytokine that induces cardiac myocyte hypertrophy. Proc Natl Acad Sci USA 92:1142-1146.

Pennica D, Arce V, Swanson T, Vejsada R, Pollock R, Armanini M, Dudley K, Phillips H, Rosenthal A, Kato A, Henderson CE (1996) Cardiotrophin-1, a cytokine present in embryonic muscle supports long-term survival of spinal motoneurons. Neuron 17:63-74.

Rickenbacher J, Müller E (1979) The development of cholinergic ganglia in the chick embryo. Anat Embryol (Berl) 155:253-258.

Rosoff ML, Wei J, Nathanson NM (1996) Isolation and characterization of the chicken $\mathrm{m} 2$ acetylcholine receptor promoter region: induction of gene transcription by leukemia inhibitory factor and ciliary neurotrophic factor. Proc Natl Acad Sci USA 93:14889-14894.

Sendtner M, Carroll P, Holtmann B, Hughes RA, Thoenen H (1994) Ciliary neurotrophic factor. J Neurobiol 25:1436-1453.

Sheng ZL, Knowlton K, Chen J, Hoshijima M, Brown JH, Chien KR (1997) Cardiotrophin 1 (CT-1) inhibition of cardiac myocyte apoptosis via a mitogen-activated protein kinase-dependent pathway: divergence from downstream CT-1 signals for myocardial cell hypertrophy. J Biol Chem 272:5783-5791.

Stahl N, Yancopoulos G (1993) The alphas, betas, and kinases of cytokine receptor complexes. Cell 74:587-590.

Stöckli K, Lottspeich F, Sendter M, Masiakowski P, Carroll P, Gotz R, Lindholm D, Thoenen H (1989) Molecular cloning and regional distribution of rat CNTF. Nature 343:920-923.
Stoop R, Poo M-M (1995) Potentiation of transmitter release by ciliary neurotrophic factor requires somatic signaling. Science 267:695-699.

Sun Y, Rao MS, Zigmond RE, Landis SC (1994) Regulation of vasoactive intestinal peptide expression in sympathetic neurons in culture and after axotomy: the role of cholinergic differentiation factor/leukemia inhibitory factor. J Neurobiol 25:415-430.

Symes A, Gearan T, Eby J, Fink JS (1997) Integration of Jak-STAT and Ap-1 signaling pathways at the vasoactive intestinal peptide cytokine response element regulates ciliary neurotrophic factor-dependent transcription. J Biol Chem 272:9648-9654.

Wang X, Halvorsen SW (1998) Retinoic acid upregulates ciliary neurotrophic factor receptors in cultured chick neurons and cardiomyocytes. Neurosci Lett 340:9-12.

Wishingrad MA, Koshlukova S, Halvorsen SW (1997) Ciliary neurotrophic factor stimulates the phosphorylation of two forms of STAT3 in chick ciliary ganglion neurons. J Biol Chem 272:19752-19757.

Wollert KC, Taga T, Saito M, Narazaki M, Kishimoto T, Glembotski CC Vernallis AB, Heath JK, Pennica D, Wood WI, Chien KR (1996) Cardiotrophin-1 activates a distinct form of cardiac muscle cell hypertrophy: assembly of sarcomeric units in series via gp130 leukemia inhibitory factor receptor-dependent pathways. J Biol Chem 271:9535-9545.

Yang Y-C (1993) Interleukin 11: an overview. Stem Cells 11:474-486.

Yoshida K, Taga T, Saito M, Suematsu S, Kumanogoh A, Tanaka T, Fujiwara H, Hirata M, Yamagami T, Nakahata T, Hirabayashi T, Yoneda Y, Tanaka K, Wang WZ, Mori C, Shiota K, Yoshida N, Kishimoto T (1996) Targeted disruption of gp130, a common signal transducer for the interleukin 6 family of cytokines, leads to myocardial and hematological disorders. Proc Natl Acad Sci USA 93:407-411. 